\title{
A Compositional Analysis of Anti-Quantifiers as Quantifiers
}

\author{
Malte Zimmermann \\ University of Amsterdam
}

\section{Introduction}

This paper presents a surface-compositional analysis of the construction in (1ab).
a. The boys
bought
three sausages each.
b. Die Jungen kauften jeweils drei Würstchen. the boys bought each three sausages
[German]

The sentences in ( $1 \mathrm{ab}$ ) contain a distributive element that forms a constituent with an indefinite (mostly numeral) expression (the 'DistShare'). The distributive element distributes the denotation of the DistShare over the denotation of a clausemate plural expression (the 'DistKey').

In the literature, this construction is known under various names, including 'shifted each' (Postal 1975), 'anti-quantifier' (Choe 1987), and 'binominal each' (Safir \& Stowell 1988). It has the following characteristic properties (cf. Choe 1987, Safir \& Stowell1988, Junker 1995). As mentioned, the DistShare must be an indefinite (or better: non-specific) expression.

(2) *The boys love the woman / every woman / that woman each.

Second, the DistKey must be a plural expression.

$$
\text { *Peter / *the Prime Minister / *that man loves two women each. }
$$

Third, distributive element and DistKey must be clausemates.

*The store clerks said that Peter had bought one balloon each.

intended reading: 'Each of the store clerks said that there was one (different) balloon that Peter had bought.'

Finally, observe that the construction is found in a range of related and unrelated languages.
a. De jongens
hebben elk
elk twee boeken gelezen.
[Dutch] the boys have each two books read
b. Guttene har kjøpt to pølser hver. boys-the have bought two sausages each
c. Strákarnir keyptu tvær pylsur hvorl hver. boys-the bought two sausages each $_{\text {dual }}$ each $_{\mathrm{pl}}$


d. Les professeurs ont lu deux livres chacun. [French] the professors have read two books each (Tellier \& Valois 1993:574, ex.1a)

e. I ragazzi comprarono un libro the boys bought a book (Burzio1986:198, ex.50b)

f. Mal'chiki kupili po dve sosiski kazhdyj. [Russian] boys ${ }_{\text {NOM }}$ bought PREP two sausages each 'The boys bought two sausages each.'

g. John i Mary kupicha po edna tetradka. [Bulgarian] John and Mary bought PREP one notebook 'John and Mary bought a notebook each.' (Petrova 2000, ex.7)

h. Otoko=tati-ga sorezore huta=ri-no zyosei-o aisi teiru] koto.[Jap.] men=pl - NOM each two=cl-GENwomen- ACC love-asp fact 'The men love two women each.' (Sakaguchi 1998:115,ex.1)

i. ai-tul-i phwungsen-hana-ssik-ul sa-ess-ta. [Korean] child-pl-NOM balloon one each ACC bought

'The children bought a balloon each.' (Choe 1987:49,ex.13)

The widespread occurrence of the construction suggests that we deal with a general, possibly universal phenomenon here.

\section{Two Problems}

The construction in (1ab) raises two questions for the syntax-semantics interface. I will refer to these as the 'Compositionality Problem' and the 'Cross-Linguistic Problem' respectively.

\subsection{The Compositionality Problem}

The overt position of English each and German jeweils in (1) is problematic for surface-compositionality. This is illustrated schematically in (6ab).

(6) a. The boys bought [DP [three sausages] each].

b. $\forall \mathrm{x}\left[\right.$ boy' $^{\prime}(\mathrm{x}) \rightarrow \exists \mathrm{y}[$ [3ausages' $(\mathrm{y}) \& \mathrm{x}$ bought $\left.\left.\mathrm{y})\right]\right]$

Unlike other adnominal quantifiers, the distributive quantifiers in (1) appear not to form a syntactic unit with their semantic restriction (the boys). Instead, they form a constituent with the DistShare three sausages (cf. Choe 1987, Stowell \& Safir 1988, Junker 1995, Zimmermann, in prep.). ${ }^{1}$ In other words, the distributive quantifiers seems to be in the wrong syntactic position from a semantic point of view. For this reason, Choe (1987) calls them 'Anti-Quantifiers' (= 'AQs').

Existing analyses of AQs (e.g. Link 1986/98, Choe 1987, Junker 1995, Moltmann 1991, Moltmann 1997, Sauerland 2001) try to reconcile the clash 
between overt syntax and semantic interpretation in various ways, but all of them have in common that they are not surface-compositional.

\subsection{The Cross-Linguistic Problem}

The second question is how to account for an observable cross-linguistic difference regarding the nature of the DistKey. English each (and AQs in Dutch, Norwegian, French, Italian, Russian) seem unable to distribute over pluralities of events, or other abstract entities (facts, situations, etc) (cf. 7ab). In contrast, German jeweils (and AQs in Korean and Bulgarian) can do so (cf. 8ab).

a. *Peter praised and criticised Mary for two reasons each. (OK with respectively)

b. *One apple each was rotten. intended reading: 'One apple was rotten each time / in each basket.'

a. Peter lobte und kritisierte Maria aus jeweils zwei Gründen. Peter praised and criticised Maria for each two reasons 'Each of Peter's praising Mary and his criticising her happened for two reasons.'

b. Jeweils ein Apfel war verrottet. each one apple was rotten

'One apple was rotten each time / in each basket etc..'

\subsection{Goals}

Given the two problems in 2.1 and 2.2, the paper is structured as follows. Section 3 provides a surface-compositional analysis of AQs. In particular, it will be argued that AQs are instances of regular quantifiers after all. Section 4 accounts for the general possibility of event-related readings with AQs, which was illustrated in (8ab). Section 5 accounts for the cross-linguistic difference regarding the availability of such event-related readings illustrated in (7) and (8).

\section{A Surface-Compositional Analysis of Anti-Quantifiers as Quantifiers}

\subsection{Basic Assumptions}

In this section, I argue that a surface-compositional interpretation of the sentences in (1ab) is possible given a number of syntactic and semantic assumptions. The analysis is based on the assumption that the internal structure of the DP containing the AQ is more complex than meets the eye. In this section, I lay out the general assumptions for the compositional analysis of AQs. In 3.2, I show how the meaning of DPs containing AQs is derived. In 3.3, I show how the meaning of such DP combines with the remainder of the clause. 
The first assumption is that AQs are regular quantifiers that take an NPproform as complement. This NP-proform is co-indexed with the plural DistKey and restricts the AQ semantically. Schematically, this is illustrated in (9).

$$
\left.\left.\operatorname{DistKey~}_{\mathrm{i}} \ldots\left[\text { [DP... [QP AQ [NP } \text { proform }_{\mathrm{i}}\right]\right]\right]
$$

(9) shows that the AQ combines syntactically with its restriction (the proform), solving the apparent mismatch between overt syntax and semantic representation. The proform gets its value under co-indexation with DistKey. In English (each) and Dutch $(e l k)$, the proform must be taken to be covert (see Safir \& Stowell 1988), but in other languages it is expressed overtly. German: je-weil-s; French: chacun(e) (Junker 1995); Italian: ciascuno/a
each-time-GEN each-one each-one

The second assumption is that the indefinite DistShare expression denotes a predicate (over pluralities). The DistShare specifies the nature of the entities that distribute over the DistKey denotation. In the example in (1ab), the DistShare specifies that the distributed entities are pluralities consisting of three sausages.

The third assumption is that DPs containing an AQ (henceforth 'eachDPs') are structurally complex. The functional $D^{0}$-head selects for a DP-internal small clause, a $\operatorname{Pr}$ (edication)P (Bowers 1993), as in (11).

(11) a. The boys $s_{i}$ bought $\left[D P\right.$ three sausages each $\left.{ }_{i}\right]$.

b.

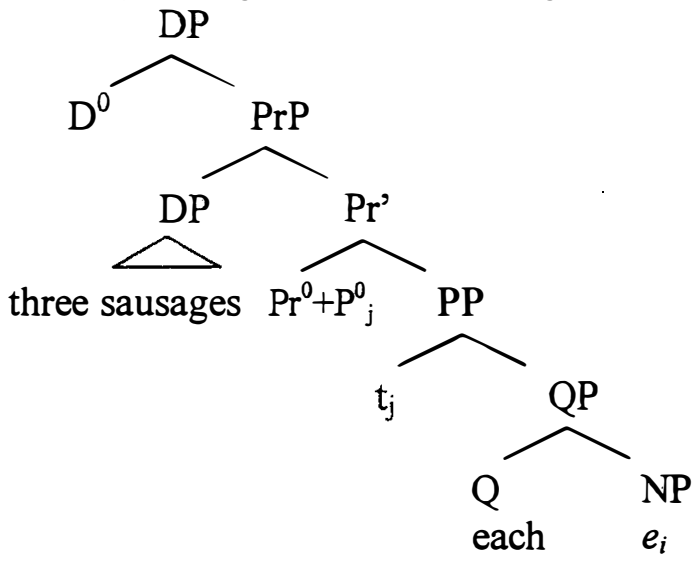

The existence of DP-internal small clauses is argued for in Abney (1987) and Bowers (1993). In (11), the PP is the syntactic predicate of the small clause. The DistShare is its syntactic subject. The AQ and its NP-proform form part of the PP. The zero head $\mathrm{P}^{0}$ incorporates into the head of the small clause, $\operatorname{Pr}^{0}$. In the case of German jeweils, the postnominal PP moves (optionally) to SpecDP, in analogy to den Dikken's (1998) operation of DP-internal predicate fronting.

The presence of a PP is motivated independently. In German, the P-head is marked overtly in form of genitive marking (jeweil-s). In Russian (5f) and Bulgarian (5g) it is realised lexically by means of the preposition $p o$. 
The fourth assumption is that the prepositional head $\mathrm{P}^{0}$ denotes a relation variable ' $R$ '. ' $R$ ' establishes a distributive relationship between DistKey and DistShare. ' $R$ ' is co-indexed with an overt relation-denoting expression that provides it with its semantic value. ${ }^{2}$ In the case of (lab), the overt relationdenoting expression is the transitive verb buy. As a result, the distributive relation between individual boys and sets of three sausages is one of buying, and not, say, of eating, craving etc.

\subsection{The Denotation of each-DPs}

In this section, I claim that each-DPs are interpretable as in (12). ${ }^{3}$ I assume that the distributive effect is due to the presence of a Skolem function (type $<\mathrm{e}, \mathrm{e}>$ ). The semantic nature of the Skolem function is determined by the denotation of $\operatorname{PrP}$, which denotes a set of such Skolem functions). The Skolem function maps elements of the restriction to elements of the DistShare in a way specified by ' $R$ ':

(12) Semantic Analysis, Part I:
a. $[[\mathrm{Pr}+\mathrm{P}]]=\lambda \mathrm{Q}_{<\mathrm{et}, \mathrm{t}>} \lambda \mathrm{P}_{<\mathrm{e}, \mathrm{t}>} \lambda \mathrm{f}_{<\mathrm{e}, \mathrm{e}>\mathrm{Q}} \mathrm{Q}\left(\lambda \mathrm{x} . \mathrm{P}(\mathrm{f}(\mathrm{x})) \& \mathrm{R}_{\mathrm{j}}(\mathrm{f}(\mathrm{x}))(\mathrm{x})\right)$
b. $\left[\left[\mathrm{QPeach}_{-} \mathrm{e}_{\mathrm{i}}\right]\right]=\lambda \mathrm{P} . \forall \mathrm{z}\left[\mathrm{z} \in \mathrm{Z}_{\mathrm{i}} \rightarrow \mathrm{P}(\mathrm{z})\right]$ by $F A$ of $[[$ each $]]$ to $\left[\left[e_{\mathrm{i}}\right]\right]$
$\Downarrow$ by $F A$ of (12a) to (12b)
c. $\left[\operatorname{Pr}^{0}+\mathrm{P}^{0}\right.$ each-e $\left.\left.\mathrm{e}_{\mathrm{i}}\right]\right]=\lambda \mathrm{P}_{<\mathrm{et}, \mathrm{t}>} \lambda \mathrm{f}_{<\mathrm{e}, \mathrm{e}>\mathrm{.}} \forall \mathrm{z}\left[\mathrm{z} \in \mathrm{Z}_{\mathrm{i}} \rightarrow\left(\mathrm{P}(\mathrm{f}(\mathrm{z})) \& \mathrm{R}_{\mathrm{j}}(\mathrm{f}(\mathrm{z}))(\mathrm{z})\right)\right]$
$\Downarrow$
d. [ $\left[\operatorname{PrP}_{\mathrm{P}}\right.$ three sausages each- $\left.\left.\mathrm{e}_{i}\right]\right]$
by $F A$ of $(12 c)$ to [[three sausages]]
$=\lambda \mathrm{f} . \forall \mathrm{z}\left[\mathrm{z} \in \mathrm{Z}_{\mathrm{i}} \rightarrow\left(\right.\right.$ (3sausages' $\left.\left.(\mathrm{f}(\mathrm{z})) \& \mathrm{R}_{\mathrm{j}}(\mathrm{f}(\mathrm{z}))(\mathrm{z})\right)\right]$
$\Downarrow \quad$ by $F A$ of $\left[\left[D^{0}\right]\right]$ to $(12 d)\left(\right.$ with $\left.\left[\left[D^{0}\right]\right]=\lambda F . \exists f F(f)\right)$
e. $\left[\left[D_{P} D^{0}\right.\right.$ three sausages each-e $\left.\left.e_{i}\right]\right]$ $=\exists f\left[\forall z \in Z_{i} \rightarrow\right.$ (3sausages' $\left.\left.(f(z)) \& R_{j}(f(z))(z)\right)\right]$

As can be seen from the right-hand expression in (12e), each-DPs denote open propositions. The each-DP in (12e) is true iff there is a Skolem function $\mathrm{f}$, such that $f$ maps each element $z$ of a given set $Z$ into a set of three sausages such that a certain relation $R_{j}$ holds between $\mathrm{z}$ and its function value.

The assumption that each-DPs are proposition-denoting is supported by the fact that there are other proposition-denoting DPs, even in English. Consider the constructions in (13).

(13) a. [One apple [Pp on every plate]] is too much / sufficient. 'It is too much/ sufficient that there be one apple on every plate.'

b. [John singing the Marseillaise] annoyed me, 'It annoyed me that John sang the Marseillaise.' 
The subject DP in (13a), which arguably has the same structure as the DP in (11a) modulo an overt preposition, seems to be the semantic argument for propositional operators such as too much, or sufficient. Such operators normally take arguments of type $\langle t>$, i.e. propositions. Being the only potential argument, the subject DP in (13a) should be of type $<t>$ as well, as indicated by the paraphrase. Similarly, Abney (1987) analyses the bracketed ACC-ing gerund in (13b) as a DP although its denotation seems to be the proposition that John sang the Marseillaise. According to Abney (1987:143), the only noun-phrase property of ACC-ing gerunds is their external syntactic distribution.

The existence of proposition-denoting DPs is by no means restricted to English. To the contrary, proposition-denoting expressions with the syntactic distribution and/or other properties typical of DPs (case marking, nominal classifiers) are cross-linguistically attested. In Finnish, embedded clauses under certain verbs of saying or believing can carry an accusative marker on the nonfinite verb. ${ }^{4}$
a. Luul-i-n [teidän tunte-va-n isoglossin käsitteen]. believe-past-I you y $^{-G E N ~ k n o w-p t c-A C C ~ i s o g l o s s e s ~ n o t i o n ~}$ 'I thought that you knew the notion of isoglosses.' (Hakulinen \& Karlsson 1979)
b. Metsästäjä ampui lehmä-n. (Hakulinen \& Karlsson 1979) hunter shot cow-ACC
'The hunter shot the/a cow.'

In Tsez, the verb of an embedded clause can carry a noun class marker.

$$
\begin{aligned}
& \text { enir [ užā magalu bāc'ruti] } \text { r-iyxo } \\
& \text { mother boy bread.III.ABS ate].IV IV-know } \\
& \text { 'The mother knows that that the boy ate the bread.' } \\
& \text { (Bobaljik 2001, ex. 14a, citing Polinsky \& Potsdam 2001) }
\end{aligned}
$$

This concludes the brief excursus on proposition-denoting DPs across languages. The data in (13) - (15) constitute evidence on favour of analysing each-DPs as being propositional in nature.

\subsection{Combining the Meanings of each-DP and its Syntactic Sister}

It still needs to be shown how each-DP and its syntactic sister combine semantically. I assume that the meaning of the each-DP combines with the meaning of its sister by means of the semantic rule in (16):

(16) Index-triggered $\lambda$-Abstraction (inspired by Bittner 1994):

If the semantic types of a proposition-denoting expression $\alpha$ and its syntactic sister $\beta$ do not match, and if $[[\alpha]]$ contains a free variable $u_{i}$ which shares its index ' $i$ ' with $\beta, \lambda$-abstraction in $[[\alpha]]$ over index ' $i$ ' is licensed, and $\lambda u_{i} .[[\alpha]]$ is a value of $\alpha .^{5}$ 
The rule in (16) is not restricted to the interpretation of each-DPs. To the contrary, it can be employed elsewhere, e.g. in the interpretation of moved elements (cf. 17a), or hanging topics (cf. 17b).
a. [IP Peter [vp $_{\mathrm{i}}$ bought a car]]

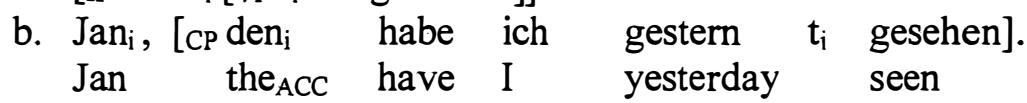 'As for Jan, I have seen him yesterday.'

In a way, (16) can be perceived as a generalisation of the idea behind Heim \& Kratzer's (1998) rule for interpreting moved constituents. In (18), it is shown how application of (16) allows for a correct interpretation of (17b), where the hanging topic has not been moved to sentence-initial position, but is base-generated in this position (cf. e.g. Weerman 1988). This goes to show that the rule in (16) has a wider range of applications than Heim \& Kratzer's rule. ${ }^{6}$
a. [[den $n_{i}$ habe ich gestern $t_{i}$ gesehen $\left.]\right]$ $=\underset{\Downarrow}{\exists}\left[\operatorname{seen}^{\prime}\left(\mathrm{I}, \mathrm{x}_{\mathrm{i}}, \mathrm{e}\right) \wedge \mathrm{at}^{\prime}(\mathrm{e}\right.$, yesterday $\left.)\right]$ $\lambda$-abstraction triggered by (16)
b. [[den $n_{i}$ habe ich gestern $t_{i}$ gesehen]] $=\lambda \mathrm{x}_{\mathrm{i}} . \exists \mathrm{e}\left[\operatorname{seen}^{\prime}\left(\mathrm{I}, \mathrm{x}_{\mathrm{i}}, \mathrm{e}\right) \wedge\right.$ at' $(\mathrm{e}$, yesterday $\left.)\right]$ $\Downarrow$ FA of $(18 b)$ to $\left[\left[\mathrm{Jan}_{i}\right]\right]$
c. $\left[\left[\operatorname{Jan}_{i}\right.\right.$, den $_{i}$ habe ich gestern gesehen $\left.]\right]$ $=\exists e\left[\right.$ seen' $^{\prime}\left(I, j^{\prime}{ }^{\prime}, e\right) \wedge$ at' $(e$, yesterday $\left.)\right]$

(18c) is true iff there is an event of the speaker seeing Jan that took place yesterday.

With (16) in place, we can proceed to the second part of the semantic analysis of (1a). The meanings of each-DP and V in (1a) combine by $\lambda$ abstraction over index ' $j$ ' of ' $R_{j}$ ' in [[DP]], followed by functional application of the result to [[V]] (which provides the 'content' of the distributive relation). This is illustrated schematically in (19)

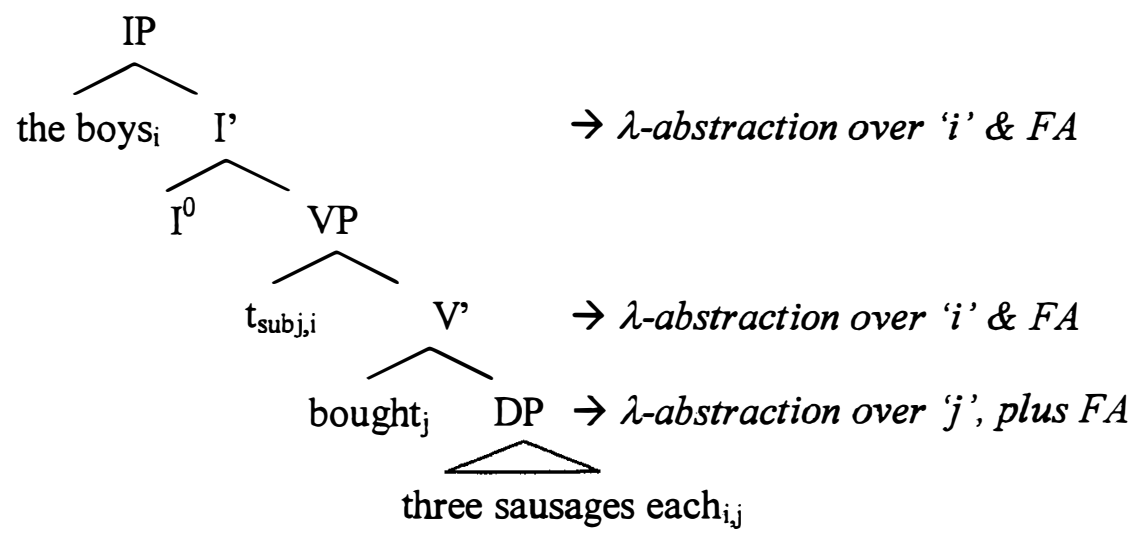


Application of index-triggered $\lambda$-abstraction over 'j' in [[DP]] yields (20a). FA of (20a) to the verb meaning yields (20b).
a. $\quad \lambda R . \exists f\left[\forall z \in Z_{i} \rightarrow(\right.$ ssausages' $\left.(\mathrm{f}(\mathrm{z})) \wedge \mathrm{R}(\mathrm{f}(\mathrm{z}))(\mathrm{z}))\right]$
by $\lambda$-abstraction over ' $j$ ' in (12e)
$\Downarrow$
b. [[bought $\left[\right.$ [DP two sausages each $\left.\left.-e_{i}\right]\right]$
by FA of (20a) to [[bought]]

$$
\begin{aligned}
& =\left(\lambda \mathrm{R} . \exists \mathrm{f}\left[\forall \mathrm{z} \in Z_{\mathrm{i}} \rightarrow(3 \text { sausages'(f(z)) } \wedge \mathrm{R}(\mathrm{f}(\mathrm{z}))(\mathrm{z}))\right]\right)(\lambda x \lambda \mathrm{y} \text {. y bought } \mathrm{x}) \\
& =\exists \mathrm{f}\left[\forall \mathrm{z} \in Z_{\mathrm{i}} \rightarrow(3 \text { sausages' }(\mathrm{f}(\mathrm{z})) \wedge \text { bought' }(\mathrm{f}(\mathrm{z}))(\mathrm{z}))\right]
\end{aligned}
$$

A second application of $\lambda$-abstraction over index ' $i$ ' of the free variable $Z_{\mathrm{i}}$, followed by FA to the subject (trace) denotation gives the correct truth conditions for (1a). (21b) is true iff the boys bought three sausages each.

a. $\exists f[\forall z \in[[$ the boys] $] \rightarrow($ sausages' $(f(z)) \wedge$ bought'( $(\mathrm{z}(\mathrm{z}))(\mathrm{z}))])=1$ iff

b. There is a function such that for each boy $z, f(z)$ constitutes a set of three sausages and $\mathrm{z}$ buys $\mathrm{f}(\mathrm{z})$.

In conclusion, a surface-compositional interpretation of $\mathrm{AQs}$ is possible taking the syntactic structure in (11b) as input. It was shown that anti-quantifiers are regular quantifiers in a peculiar syntactic (and semantic) environment. Furthermore, the properties of the AQ-construction, which were presented in section 1, follow from its semantics: (i.) the semantics of $\operatorname{Pr}^{0}+P^{0}$ require a predicate-denoting, i.e. non-specific DistShare expression; (ii.) the semantics of the $\mathrm{AQ}$ require a plural denoting DistKey that provides the restriction for the universal quantifier under co-indexation with the NP-proform; (iii.) the semantic representation in (20b) contains only one free variable as a target for $\lambda$ abstraction. This variable provides the universal quantifier with its restriction. It follows that the subject (trace) must be interpreted as the restriction of the universal quantifier. Intervening singular subjects cannot be skipped for the sake of a plural DistKey in a higher clause (cf. 4), for there is no alternative way to interpret the intervening subject, causing the semantic derivation to crash. In the next section, I show that the proposed semantic mechanism also allows for the derivation of event-related readings with AQs.

\section{Accounting for Event-Related Readings with AQs}

In this section, I argue that event-related readings with German jeweils in (22ab) are also derivable by the semantic mechanism proposed above. ${ }^{7}$

a. Peter 2 hat Maria ${ }_{1}$ bei ${ }_{j}$ jeweils $s_{i j}$ zwei Anlässen [vp $\mathrm{t}_{2} \mathrm{t}_{1}$ [gelobt und Max has Maria at each two occasions praised and kritisiert]] . criticised

'Peter criticised and praised Maria for two reasons respectively.' 
b. [Jeweils $s_{i, j}$ ein Apfel $]_{1} \quad$ [vP $\mathrm{t}_{1}$ war verrottet]. each one apple was rotten 'One apple was rotten each time / in each basket etc..'

\subsection{Distribution over VP-conjuncts}

The semantic derivation of (22a) is analogous to that of (1ab), the difference being that universal quantification ranges over a plurality of event predicates. The DistKey in (22a) is a plural event (predicate) of praising and criticising that is denoted by the "pluralised" VP-conjunction. The denotations of the two conjoined VPs combine to form a plural predicate (over events) by Krifka's (1990) mechanism of plural predicate formation (cf.23d). The DistShare zwei Anlässen 'two occasions' denotes sets of two occasions on which the individual subevents took place. The relation variable ' $R$ 'gets its semantic value under co-indexation not with a transitive verb, but with the preposition bei 'at'.

a. [[jeweils $\mathrm{s}_{\mathrm{j}, \mathrm{j}}$ zwei Anlässen]]

$=\exists f\left[\forall z\left[z \in Z_{i} \rightarrow\left(2 o c\right.\right.\right.$ casions' $\left.\left.\left.(f(z)) \wedge R_{j}(f(z))(z)\right)\right]\right]$

$\Downarrow \quad \lambda$-abstraction over index ' $j$ ' (triggered by co-indexation on bei)

b. [[jeweils $\mathrm{s}_{\mathrm{j}, \mathrm{j}}$ zwei Anlässen]]

$=\lambda R \cdot \exists \mathrm{f}\left[\forall \mathrm{z}\left[\mathrm{z} \in Z_{\mathrm{i}} \rightarrow(\right.\right.$ 2occasions' $\left.\left.(\mathrm{f}(\mathrm{z})) \wedge \mathrm{R}(\mathrm{f}(\mathrm{z}))(\mathrm{z}))\right]\right]$

$\Downarrow$

c. [[pp bei jeweils $\mathrm{s}_{\mathrm{i}, \mathrm{j}}$ zwei Anlässen]]

FA of $(23 b)$ to $[[b e i]]=\lambda x \lambda e . a t^{\prime}(x, e)$

$=\exists f\left[\forall z\left[z \in Z_{i} \rightarrow\left(2 o c c a s i o n s^{\prime}(f(z)) \wedge\right.\right.\right.$ at' $\left.\left.(f(z), z)\right]\right]$

d. [[vpt $\mathrm{t}_{1}$ gelobt und kritisiert]] by plural predicate formation

$=\lambda \mathrm{E} . \mathrm{E}=\mathrm{e}_{1} \oplus \mathrm{e}_{2} \wedge \operatorname{praised}^{\prime}\left(\mathrm{u}_{2}, \mathrm{v}_{1}, \mathrm{e}_{1}\right) \wedge \operatorname{criticised}^{\prime}\left(\mathrm{u}_{2}, \mathrm{v}_{1}, \mathrm{e}\right)$

$\Downarrow \lambda$-abstraction in (23c) over index ' $i$ ' (triggered by index on VP)

e. [[pp bei jeweils $\mathrm{i}_{\mathrm{ij}} z w e i$ Anlässen]]

$=\lambda Z_{\mathrm{i}} . \exists \mathrm{f}\left[\forall \mathrm{z}\left[\mathrm{z} \in \mathrm{Z}_{\mathrm{i}} \rightarrow(\right.\right.$ 2occasions' $(\mathrm{f}(\mathrm{z})) \wedge$ at' $\left.(\mathrm{f}(\mathrm{z}), \mathrm{z})]\right]$

$\Downarrow \quad$ Predicate Modification (PM) of (23d) and (23e)

f. [[ bei $i_{j}$ jeweils $s_{i, j} z w e i$ Anlässen [ $t_{2} t_{1}$ gelobt und kritisiert $\left.\left.]_{i}\right]\right]$

$=\lambda E . E=e_{1} \oplus e_{2} \wedge$ praised' $\left(u_{2}, v_{1}, e_{1}\right) \wedge$ criticised' $\left(u_{2}, v_{1}, e\right) \wedge$

$$
\exists \mathrm{f}[\forall \mathrm{z}[\mathrm{z} \in \mathrm{E} \rightarrow(\text { (2occsasions' }(\mathrm{f}(\mathrm{z})) \wedge \text { at' }(\mathrm{f}(\mathrm{z}), \mathrm{z})]]
$$

$\Downarrow \quad$ repeated $\lambda$-abstraction over indices ' 1 ' and ' 2 ', FA to object and subject denotation, existential closure over the complex event variable $E$

g. $[[(22 a)]]=\exists E\left[E=e_{1} \oplus e_{2} \wedge\right.$ praised'(peter', maria', $\left.e_{1}\right) \wedge$ criticised'(peter', maria', e) $\wedge \exists \mathrm{f}[\forall \mathrm{z}[\mathrm{z} \in \mathrm{E} \rightarrow$ (2occasions' $(\mathrm{f}(\mathrm{z})) \wedge$ at' $\left.\left.^{\prime}(\mathrm{f}(\mathrm{z}), \mathrm{z})\right]\right]=1$ iff 
h. there is a plural event E consisting of two subevents of Peter praising Mary, and of Peter criticising Mary, and for each subevent $z$ there is a function $f$ such that $f(z)$ is a set of two occasions at which $z$ happened.

( $32 \mathrm{~h})$ is true iff each of the two subevents happened at two occasions. These are the correct truth-conditions for (22a).

Notice that the semantic derivation of (22a) differs from that of (1) in that the DistKey is a plural predicate, not a plural individual. As a result, the semantic value of the adjoined event modifier bei jeweils zwei Anlässen 'on two occasions each' and the plural VP combine not by functional application, but by predicate modification. A parallel state of affairs holds in the nominal domain for examples such as (24), where a PP-modifier containing the AQ jeweils combines with the plural nominal predicate Listen 'lists'.

(24) Die [[Listen] [ mit jeweils drei Namen]] wurden herumgereicht. the lists with each three names were passed.around 'The lists with three names each were passed around.'

It seems, then, that distribution with AQs over pluralised predicates is a general option.

\subsection{Distribution over Implicit Sets of Events}

For the semantic interpretation of (22b), we need one more semantic rule. The second rule of $\lambda$-abstraction is given in (25).

Type-Triggered $\lambda$-Abstraction:

If the semantic types of a proposition-denoting expression $\alpha$ and its syntactic sister $\beta$ do not match, and if $[[\alpha]]$ contains a free variable $u_{i}$ of the same semantic type as $\beta, \lambda$-abstraction in $[[\alpha]]$ over index ' $i$ ' is licensed, and $\lambda u_{i} \cdot[[\alpha]]$ is a value for $\alpha$.

The DistKey in (22b) is an implicit set of events provided by the context. The DistShare is constituted by individual apples. The value of ' $R$ ' is a relation between individuals and events ( $=$ the VP-denotation after $\lambda$-abstraction over index ' 1 ' of the subject trace). (26) shows how the derivation of (22b) proceeds. The crucial steps in the derivation are (26b) and (26d). Application of indextriggered $\lambda$-abstraction to the VP-denotation yields a relation-denoting expression in sister position to the jeweils-DP. This relation-denoting expression, in tum, can trigger type-triggered $\lambda$-abstraction over the relation variable $R_{j}$ in the denotation of the jeweils-DP.

a. $\left[\left[v_{p} t_{1}\right.\right.$ war verrottet $\left.]\right]=\lambda e$. rotten' $^{\prime}\left(x_{1}, e\right)$

$\Downarrow \quad$ by index-triggered $\lambda$-abstraction over index ' 1 '

b. $\left[\left[v_{P} t_{1}\right.\right.$ war verrottet $]=\lambda \mathrm{x}_{1} \lambda$ e. rotten' $\left(\mathrm{x}_{1}, \mathrm{e}\right)$ 
c. [[Dpjeweils $\mathrm{s}_{\mathrm{i}, \mathrm{j}}$ ein Apfel] $]$

$=\exists \mathrm{f}\left[\forall \mathrm{z}\left[\mathrm{z} \in \mathrm{Z}_{\mathrm{i}} \rightarrow\left(\right.\right.\right.$ l apple' $\left.\left.\left.(\mathrm{f}(\mathrm{z})) \wedge \mathrm{R}_{\mathrm{j}}(\mathrm{f}(\mathrm{z}))(\mathrm{z})\right)\right]\right]$
$\Downarrow \downarrow \quad$ bytype-triggered $\lambda$-abstraction over index ${ }^{\prime}{ }^{\prime}$

d. [[ Dpjeweils $\mathrm{s}_{\mathrm{i}, \mathrm{j}}$ ein Apfel]]

$=\lambda R_{j} . \exists f\left[\forall z\left[z \in Z_{i} \rightarrow\left(1\right.\right.\right.$ apple' $\left.\left.\left.(f(z)) \wedge R_{j}(f(z))(z)\right)\right]\right]$

$\Downarrow$

e. [[ [Jeweils $\mathrm{i}_{\mathrm{i}, \mathrm{j}}$ ein Apfel $]_{1} \mathrm{t}_{1}$ war verrottet $\left.]\right]$

by FA of (26d) to (26b)

$=\exists f\left[\forall z\left[z \in Z_{i} \rightarrow\left(1\right.\right.\right.$ apple' $\left.\left.\left.(f(z)) \wedge\left(\lambda x_{1} \lambda e \cdot \operatorname{rotten}^{\prime}\left(x_{1}, e\right)\right)(f(z))(z)\right)\right]\right]$

$=\exists \mathrm{f}\left[\forall \mathrm{z}\left[\mathrm{z} \in \mathrm{Z}_{\mathrm{i}} \rightarrow\left(\right.\right.\right.$ lapple'$\left.\left.\left.^{\prime}(\mathrm{f}(\mathrm{z})) \wedge \operatorname{rotten}^{\prime}(\mathrm{f}(\mathrm{z}), \mathrm{z})\right)\right]\right]=1$ iff

f. there is a function which maps all elements $z$ of a contextually salient set of events onto individual apples such that $f(z)$ is rotten in $z$.

(26f) is true iff, in every relevant event/situation, there was a rotten apple. The derivation in (26) is special in that (type-triggered) $\lambda$-abstraction in the left-hand sister of a mother node (here: the jeweils-DP) is contingent on the application of (index-triggered) $\lambda$-abstraction in the right-hand sister (here: the VP). In Zimmermann (in prep.) the entire process as a whole is called 'crosswise $\lambda$ abstraction'.

In conclusion, the derivation of "event-related" readings with jeweils is analogous to that of the basic case in (1). Necessary ingredients of the analysis are the two rules of $\lambda$-abstraction in (16) and (24), the semantic analysis of each-DPs from section 3 , and the semantic mechanisms of functional application, predicate modification and existential closure over events.

\section{Accounting for Cross-Linguistic Differences with AQs}

So far, the cross-linguistic problem from section 2 has not been solved. The question raised there was why a language like English (or French, Italian, Dutch, Russian, Norwegian) does not allow for event-related readings with antiquantifiers.

Two observations will help us to arrive at a solution to this problem. The first observation concerns a correlation between the morphological shape of the $\mathrm{AQ}$ in a given language and the possibility of event-related readings in that language. In a first class of languages (henceforth: class I-languages), namely in English, Dutch, French, Italian, Norwegian, and Russian, the AQ is formally identical to the regular adnominal D-quantifier corresponding to each. The AQs in these languages do not give rise to event-related readings, as shown for Dutch, French and Italian in (27a-c).

a. *Piet heeft Marie om elk twee redenen bekritiseerd en geprezen. [Du.] P. has M. for each two reasons criticised and praised

b. *Peter a adulé et critiqué Marie pour deux raisons chacun/e.[Fr.] Peter has praised and criticised Mary for two reasons each masc/fem 
c. *Peter ha apprezzato e criticato Maria per due ragioni ciascuno/a.[It.] Peter has praised and criticised Maria for two reasons each $_{\text {masc/fem }}$

In a second class of languages (class II -languages), the AQ differs formally from the regular adnominal D-quantifier. This is the case in German, where the AQ jeweils differs from the quantifier jeder 'each, every', in Korean, where the AQ $s s i k$ - differs from the quantifier kak...mata 'every', and in Bulgarian, where the $\mathrm{AQ}$ po differs from the quantifier vseki 'each'. It turns out that these languages allow for event-related readings with AQs, as shown in section 4 for German, and in (28ab) for Korean and Bulgarian.

a. Na-nun [phwungsen-hana-ssik-ul] sa-ess-ta I TOP balloon one ACC bought

[Korean] 'I bought a balloon each time / each day / at each store.'

(Choe 1987:52, ex.18)

b. Mary byaga po 5 mili predi zakuska. Mary runs each 5 miles before breakfast

[Bulgarian] 'Mary runs 5 miles before breakfast every day.'

The first observation can be summarised in form of the generalisation in (29).

(29) i. The AQ must distribute over DP-denotations if it is formally identical to the regular adnominal D-quantifier.

ii. The AQ can distribute over non-DP denotations (implicit or explicit pluralities of events) if it is formally different from the regular adnominal D-quantifier.

The second observation is that there is no general sortal (ontological) restriction that forbids the English AQ each (and its counterparts in class I-languages) from distributing over events as long as these events are denoted by a DP. In (30), each can distribute over the two events denoted by the DP-conjunction.

[The hailstorm and the accident $]_{\mathrm{i}}$ caused five casualties each ${ }_{\mathrm{i}}$.

(30) shows that the ban on event-related readings in class I-languages is not semantically motivated, but must be syntactic in nature.

I assume that the ban has to do with the morphosyntactic feature content of the AQs in these languages, which is reflected in their morphological shape (formal identity to the adnominal D-quantifier). In brief, I assume that AQs that are formally identical to regular D-quantifiers contain D-features (person, number, gender), and that these D-features need to be checked against those of their NP-proform complement. In order to acquire D-features, the NP-proform must be co-referent (co-indexed) with a DP-expression. This explains why AQs in class I-languages cannot distribute over pluralities of events that are not denoted by a DP (i.e. events that are either implicit (cf.22b), or denoted by a VP- 
conjunction (cf.22a)). It also explains why distribution over pluralities of events is possible as long as these pluralities are denoted by a DP (cf.30).

In contrast, AQs that differ formally from regular D-quantifiers do not contain D-features that need to be checked against those of the NP-proform. It follows that the NP-proform can be co-referent (co-indexed) with any plural expression (plural DP, verb conjunction, implicit set of events). This accounts for the free availability of event-related readings with AQs in class II-languages.

In conclusion, it was shown that the cross-linguistic difference in the availability of event-related readings is syntactic in nature. AQs come in two classes cross-linguistically. In class I-languages they contain D-features that need to be checked against a DistKey DP. In class II-languages, they do not contain Dfeatures and can take any plurality as DistKey.

\section{Conclusion \& Further Applications}

In this paper, it was shown that a surface-compositional treatment of AQconstructions is possible, and that the term 'AQ' is a misnomer. Anti-quantifiers are quantifiers with an overt or covert proform. The analysis extends to a variety of languages. Cross-linguistic differences exhibited by the construction seem to be syntactic in nature.

Finally, as suggested in Zimmermann (in prep.) the analysis possibly extends to a number of related and (at first sight) unrelated constructions. These are illustrated in (31).

a. je $+N P$ constructions in German \& per-constructions in English: Benzin kostet drei Mark je Liter. petrol costs three marks per liter

b. Binding from Inverse Linking Constructions

One man in every $y_{i}$ city is rich / despises $i_{i}$.

c. Variable binding with possessor DPs

Every $_{\mathrm{i}}$ man's mother adores him . $_{\text {. }}$

d. Pluractional Prepositional Constructions (cf.Stockall 2001) Girl after girl arrived.

The interested reader is referred to Zimmermann (in prep.) for further details.

\section{Appendix: An Alternative Analysis without Small Clauses}

Zimmermann (in prep.) presents an alternative analysis of AQ-constructions that does not make use of DP-internal small clauses. On this alternative analysis, the 
postnominal PP containing the $\mathrm{QP}$ is base-generated as a postnominal PPmodifier, right-adjoined to NP. The alternative syntactic structure is given in (32).

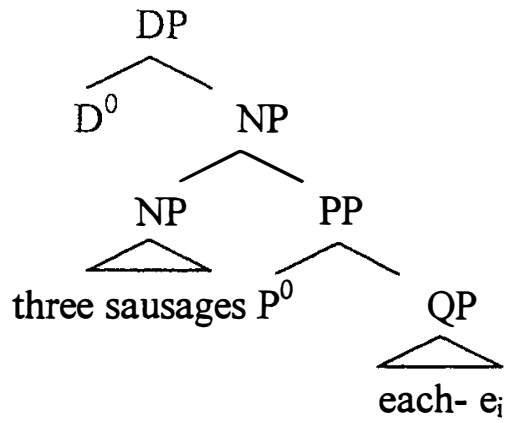

Semantically, $\mathrm{P}^{0}$ and $\mathrm{QP}$ are taken to form a lexicalised semantic unit with the denotation in (33):

a. $\left[\left[\mathrm{PP}^{\mathrm{P}} \mathrm{P}_{\mathrm{j}}\right.\right.$ each-e $\left.\left.\mathrm{e}_{\mathrm{i}}\right]\right]=\lambda \mathrm{P} . \forall \mathrm{z}\left[\mathrm{z} \in \mathrm{Z}_{\mathrm{i}} \rightarrow \exists \mathrm{x}\left[\mathrm{P}(\mathrm{x}) \wedge \mathrm{R}_{\mathrm{j}}(\mathrm{x})(\mathrm{z})\right]\right]$

$\Downarrow$

b. [[ three sausages $\mathrm{P}^{0}{ }_{\mathrm{j}}$ each- $\left.\left.\mathrm{e}_{\mathrm{i}}\right]\right]$ by FA of (32a) to [[two books]] $=\forall z\left[z \in Z_{i} \rightarrow \exists x\left[3\right.\right.$ sausages' $\left.\left.^{\prime}(x) \wedge R_{j}(x)(z)\right]\right]$

c. $=\left[\left[\mathrm{DP}^{0}\right.\right.$ three sausages $\mathrm{P}^{0}{ }_{\mathrm{j}}$ each- $\left.\left.\mathrm{e}_{\mathrm{i}}\right]\right]$

On this analysis, the $\mathrm{D}^{0}$-head is semantically empty. The rest of the derivation proceeds as in (19)-(21) above (double application of $\lambda$-abstraction over indices ' $j$ ' and ' $i$ ', followed by functional application to the values of transitive verb, and subject (trace) respectively.

The advantage of the alternative analysis is that it allows for a unified analysis of adnominal jeweils and adverbial jeweils in German. (34) contains an instance of adverbial jeweils, for which a small-clause analysis seems implausible.

$\begin{array}{lll}\text { Peter hat } & \text { jeweils } & \text { gewonnen. } \\ \text { Peter has } & \text { each-time } & \text { won }\end{array}$

'Peter won each time.'

The semantic value for jeweils in (33a) extends to instances of adverbial jeweils on the assumption that $Z_{i}$ is co-indexed with a contextually salient set of events, $x$ ranges over events, and $R$ a (contextually determined) relation between two events (e.g. subpart, temporal overlap/ succession)

On the other hand, there is also a disadvantage to the alternative analysis. It treats AQs such as jeweils as special (possibly grammaticalised) forms with a particular (double quantifier) semantics. This may be plausible for the morphologically marked form jeweils, but less so for English each. 


\section{Endnotes}

1 The constituency of AQ and DistShare is confirmed by standard constituent tests. For instance, both elements can be displaced together, as shown in (i).

(i) One interpreter each $\mathrm{w}_{1}$ was assigned $t_{1}$ to the visiting diplomats.

${ }^{2}$ Relation variables are put to use in the analysis of genitive expressions by among others - Partee (1983/97), Partee \& Borshev (1998), Barker (1998). The relation variable with $\mathrm{AQs}$ differs from the relation variable with prenominal genitives, which is always semantically free and contextually bound, in that it is normally assigned a fixed value in the course of the semantic derivation.

${ }^{3}$ I take the trace of the preposition to have no effect on the semantic derivation.

${ }^{4}$ In Turkish, this is the regular strategy for clausal complements (cf. Kornfilt 1997).

${ }^{5}$ At first sight, the formulation in (16) poses a problem for compositionality (Chris Barker, p.c.). The meaning of the node consisting of $\alpha$ and $\beta$ cannot be derived by looking at the meanings of $\alpha$ and $\beta$ alone. For $\lambda$-abstraction to go through, the co-indexed free variable must be visible at the stage of the derivation where $\alpha$ and $\beta$ combine, which it is not. Apparently, the semantic derivation must look "into" the meaning of $\alpha$, of which the variable forms a part, a process not in line with compositionality. However, Dekker (1993:165f.) shows that the apparent problem for compositionality can be overcome by using partial assignment functions. See also Dekker 1998:332, fn.5, on the special case of the assignment function assigning the empty set. (Ede Zimmermann, p.c.).

6 (16) differs from Heim \& Kratzer's rule in that it does not ensure an unambiguous mapping from syntactic structure to interpretation. This fact is captured by the formulation "[...] is $a$ value for $\alpha$ " in (16). In other words, the notation ' $[[\alpha]]$ ' is not unambiguously defined. The problem is ameliorated by the fact that (16) only applies in cases where the combination of $\alpha$ and $\beta$ is uninterpretable otherwise, due to type mismatch. This ensures that the mother node of $\alpha$ and $\beta$ has an unambiguous reading in almost all cases (it either receives no interpretation, or it receives the interpretation resulting from $\lambda$-abstraction). Nevertheless, there is a configuration in which application of (16) could lead to ambiguity on the mother node in principle. The situation arises when both sisters $\alpha$ and $\beta$ are proposition-denoting, $\alpha$ is co-indexed with a free variable in the denotation of $\beta$, and $\beta$ is co-indexed with a free variable in the denotation of $\alpha$. The situation is given schematically in (i)

$$
\left[\left[\alpha_{i}\right]\left[\beta_{j}\right]\right]
$$

$$
\left(\mathrm{x}_{\mathrm{j}}\right) \quad\left(\mathrm{y}_{\mathrm{i}}\right)
$$

In this situation, $\lambda$-abstraction as in (16) can apply either to $\alpha$ (over index ' $\mathrm{j}$ ') or to $\beta$ (over index ' $i$ '). Independent of the question of whether this configuration actually arises, one should keep in mind that applying (16) to (i) results in the 
derivation of a family of readings that is passed up in the semantic derivation, rather than in the derivation of an unambiguous reading (Ede Zimmermann, p.c.).

${ }^{7}$ For expository reasons, I have slightly altered the example in (8a) to (22a). This is because (8a) is not fully transparent semantically. The preposition aus 'from' in the PP-modifier aus...Gründen 'for...reasons' seems to have lost its original meaning. Instead, the causal relational meaning is provided by the NPcomplement Gründen 'reasons'. In contrast, (22a) is fully transparent, with the preposition bei denoting the local relation AT.

\section{References}

Abney, S. (1987). The English Noun Phrase in its Sentential Aspect. PhD thesis, MIT, Cambridge, Mass.

Barker, C. (1998). Partitives, Double Genitives, and Anti-Uniqueness. Natural Language and Linguistic Theory 16. 679-717.

Bittner, M. (1994). Crosslinguistic Semantics, Linguistic and Philosophy 17. 53108.

Bobaljik, J. (2001). Agreement Domains. Presentation at ConSole X, Leiden, 6-8 December 2001.

Bowers, J. (1993). The syntax of Predication, Linguistic Inquiry 24. 591-656.

Choe, J.-W. (1987). Anti-Quantifiers and a theory of distributivity. $\mathrm{PhD}$ thesis, UMass, AmherstMA.

Dekker, P. (1993). Transsentential Meditations, $\mathrm{PhD}$ thesis, University of Amsterdam.

Dekker, P. (1998). Speaker's Reference, Descriptions, and Information Structure. Journal of Semantics 15. 305-334.

Dikken, M. den (1998). Predicate Inversion in DP. In A. Alexiadou \& Ch. Wilder (eds.), Possessors, Predicates and Movement in the Determiner Phrase. Benjamins: Amsterdam. 177-214.

Hakulinen, A. \& F. Karlsson (1979). Nykysuomen Lauseoppia. Helsinki: Suomalaisen Kirjallisuuden Seura.

Heim. I. \& A. Kratzer (1998). Semantics in generative grammar. Oxford: Blackwell.

Junker, M.-O. (1995). Syntaxe et sémantique des quantifieurs flottant 'tous' et 'chacun': distributivité en sémantique conceptuelle. Geneva: Librairie Droz.

Kayne, R. (1994). The Antisymmetry of Syntax. Cambridge: MIT Press.

Kornfilt, J. (1997). Turkish. London/New York: Routledge.

Krifka, M. (1990). Boolean and non-boolean 'and'. In L. Kálmán \& L. Pólos (eds.), Papers from the Second Symposium of Logic and Language 6. 389422.

Link, G. (1986/98). 'Je drei Äpfel - three apples each': Quantification and the German 'je'. In G. Link, Algebraic Semantics in Language and Philosophy. Stanford: CSLI Publications. 117-132. 
May, R. (1985). Logical Form - Its structure and derivation. Cambridge: MIT Press.

Moltmann, F. (1991). On the syntax and semantics of binary distributive quantifiers. Proceedings of the North East Linguistic Society (NELS) 22. 279-292.

Moltmann, F. (1997). Parts and Wholes in Semantics. Oxford: Oxford University Press.

Partee, B. (1983/1997). Uniformity vs. Versatility: the Genitive, a Case Study. In J. van Benthem \& A. ter Meulen (eds.), The Handbook of Logic and Language, Amsterdam, 464-470.

Partee, B. and V. Borshev (1998). Integrating lexical and formal semantics: genitives, relational nouns, and type-shifting. In R. Cooper and Th. Gamkrelidze (eds.), Proceedings of the Second Tbilisi Symposium on Language, Logic, and Computation.

Petrova, M. (2000). The distributive marker po in Bulgarian. Ms., USC, Los Angeles.

Polinsky, M. \& E. Potsdam (2001). Long distance agreement and topic in Tsez. Natural Language and Linguistic Theory 3. 1-19.

Postal, P. (1975). On Raising. Cambridge, Mass.: MIT Press.

Safir, K. \& T. Stowell (1988). Binominal 'each'. Proceedings of NELS 18, Amherst/MA: GLSA.

Sauerland, U. (2001). On the Syntax of Anti-Distributivity Markers. Abstract for presentation at the '16th Comparative Germanic Syntax Workshop', McGill University, Montreal.

Stockall, L. (2001). Pluractionality and Prepositions in Germanic: The Syntax and Semantics of [NP $\mathrm{p}$ NP]s. Presentation at ConSole X, Leiden, 6-8 December 2001.

Weerman, F. (1988). The V2 Conspiracy. A synchronic and a diachronic analysis of verbal positions in Germanic languages. Dordrecht: Foris.

Zimmermann, M. (in prep.). Boys Buying Two Sausages Each. On the Syntax and Semantics of Distance-Distributivity. $\mathrm{PhD}$ thesis, University of Amsterdam. 